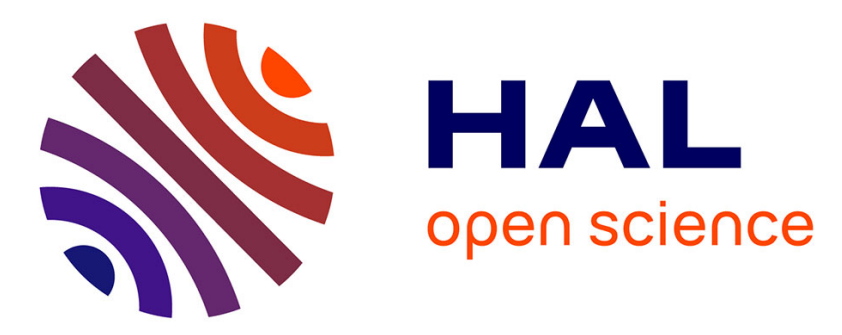

\title{
Biological conclusions about importance of order in mobbing calls vary with the reproductive context in Great Tits ( Parus major )
}

\author{
Ambre Salis, Thierry Lengagne, Jean-Paul Léna, Mylène Dutour
}

\section{- To cite this version:}

Ambre Salis, Thierry Lengagne, Jean-Paul Léna, Mylène Dutour. Biological conclusions about importance of order in mobbing calls vary with the reproductive context in Great Tits ( Parus major ). Ibis, 2021, 163 (3), pp.834-844. 10.1111/ibi.12940 . hal-03250443

\section{HAL Id: hal-03250443 \\ https://univ-lyon1.hal.science/hal-03250443}

Submitted on 26 Nov 2021

HAL is a multi-disciplinary open access archive for the deposit and dissemination of scientific research documents, whether they are published or not. The documents may come from teaching and research institutions in France or abroad, or from public or private research centers.
L'archive ouverte pluridisciplinaire HAL, est destinée au dépôt et à la diffusion de documents scientifiques de niveau recherche, publiés ou non, émanant des établissements d'enseignement et de recherche français ou étrangers, des laboratoires publics ou privés. 


\title{
Biological conclusions about importance of order in mobbing calls vary
} with the reproductive context in Great Tits Parus major

\author{
AMBRE SALIS, ${ }^{*}$ THIERRY LENGAGNE, JEAN-PAUL LENA \& MYLENE DUTOUR
}

Univ Lyon, Université Claude Bernard Lyon 1, CNRS, ENTPE, UMR 5023 LEHNA, F69622, Villeurbanne, France.

*Corresponding author.

Email: ambre.salis@univ-lyon1.fr

Currently, there is considerable debate surrounding the presence of some human language specific characteristics in non-human animals, such as the use of compositional syntax (i.e., 3 meaning of a sequence determined both by meaning of its individual parts and in the way they are combined). Compositional syntax has been investigated in mobbing calls of two closely 5 related tit species, the Japanese Tit Parus minor and the Great Tit Parus major, but with one contrasting result: hearing calls in the reversed order diminished the behavioural responses of Japanese Tits, however only partially those of Great Tits. This difference may have been due to an external factor such as the season in which the experiment was undertaken, as the Japanese 9 Tits were tested in winter and Great Tits in spring. Here, we studied the responses of Great Tits 0 towards natural and reversed mobbing sequences during spring and winter by investigating two 1 behaviours: approaching and vigilance behaviours. We found that sensitivity to syntax reversal 2 was impacted by the season. The birds were vigilant but less likely to approach reversed calls 3 in winter. However the opposite occurred in spring, with the birds scanning less but still 4 approaching. This study suggests that the perception of combinatorial calls in Great Tits is 5 influenced by the season, emphasizing the importance of context in studies investigating 6 complex cognitive processing in animals.

27 Keywords: Acoustic communication, Alarm call, Compositionality, Mobbing Behaviour, 
Animal communication is one of the most prolific subjects in animal behaviour studies

30 (Bradbury \& Vehrencamp 2011), with one major question being the extent to which we can compare it to human language. Some defining characteristics of human language are classically presented as intentionality, referentiality, vocal learning, and syntax (Hauser et al. 2002). Numerous comparative studies conducted in animal systems have focused on the first three criteria - intentionality (Seyfarth \& Cheney 2003, Graham et al. 2019), referentiality (e.g., in Siberian Jays Perisoreus infaustus, Griesser 2008), and vocal learning (e.g., song in oscines, Wilbrecht \& Nottebohm 2003, Tyack 2019) - and have revealed that these abilities are present in diverse animal species, emphasizing the importance of studying animal communication in our understanding of the evolution of language (Fishbein et al. 2019). Indeed, finding such characteristics in our closest relatives may indicate a gradual emergence of language features (Searcy 2019). In contrast, the presence of analogous traits in distant species suggests convergence: the independent rise of the same evolutionary strategy (Searcy 2019).

Birds are one great example of distant taxa possessing characteristics similar to human language, especially regarding complex combinatorial rules (i.e., a set of principles by which meaning-bearing units can be combined into well-formed complexes, Zuberbühler 2019a). However, previous findings have focused on sequences lacking direct semantic content, with many combinatorial forms being phonocoding (i.e., sound combinations whose individual parts do not possess proper meaning, Engesser \& Townsend 2019). Numerous examples of such combinatorial rules can be found in bird songs. For instance, while information about male quality is extracted from the global song, the individual syllables that make up the song do not carry specific information (Catchpole \& Slater 1995). 
Townsend 2019, Suzuki et al. 2019b, Zuberbühler 2019b). This is observed when, in opposition to phonocoding, the meaning of the whole depends on the meanings of the component parts, and the way they are organized (Hurford 2011). Cases where animals use such compositional structuring have been reported in birds when mobbing predators (Engesser et al. 2016, Suzuki et al. 2016, Suzuki et al. 2017).

Mobbing - when a prey moves towards and harasses a predator to chase it away (Carlson et al. 2018) - is a suitable behaviour to study compositional syntax. Indeed, prey produce calls to recruit mobbers from a variety of species (Hurd 1996, Randler \& Vollmer 2013, Dutour et al. 2016). In such risky situations (Curio \& Regelmann 1986), where callers and receivers have a level of shared interest, and communication should be clear and unambiguous to co-ordinate a response that combines several behaviours, it has been suggested that compositional syntax could emerge (Griesser et al. 2018). Experimental studies in the Japanese Tit Parus minor provide the strongest case of compositional syntax to date (Suzuki et al. 2016, Suzuki et al. 2017, but see also Engesser et al. 2016 on Southern Pied Babblers Turdoides bicolor). Indeed, Suzuki and colleagues demonstrated that the mobbing sequences of Japanese Tits are made through the concatenation of two types of notes Frequency modulated elements (FME) and D notes (FME-D calls), respectively triggering a vigilance and an approach behaviour - and that order has importance (Suzuki et al. 2016). Debates about these results have been profuse (Bolhuis et al. 2018a, 2018b, Suzuki et al. 2018, Townsend et al. 2018), and there is a need for broader data on potential compositionality in birds.

Dutour et al. (2019b) replicated the same experiment on a French population of Great Tits Parus major, during the breeding season. This species is the closest relative of the Japanese Tit (Päckert et al. 2005, Johansson et al. 2013) and produces similarly structured mobbing calls (FME-D calls, Fig. 1). For both species, the FME motif appears to be used in 
vigilance situations and serves as an alarm signal to which receivers respond by scanning for danger (Suzuki et al. 2016, Dutour et al. 2019b). The D notes are produced within foraging flocks and by nest mates to recruit social partners and elicit an approach by receivers (recruitment calls, Suzuki et al. 2016, Dutour et al. 2019b). Therefore, these acoustically distinct calls fulfil the first characteristic of compositionality (i.e., each different part has meaning when produced in isolation). In addition, Great Tits showed excitement signs (wing flicking and body swinging) only toward the combined FME-D calls, and never toward the isolated parts, indicating a meaning more complex than the simple sum of the isolated parts (Salis et al. 2020). The second characteristic of compositional structuring reflects the importance of organization, tested through measuring the Great Tits' response when the sequence is reversed (D-FME, demonstrated in the Japanese Tit, Suzuki et al. 2016). Here however, almost as many Great Tits approached the speaker to natural sequence (FME-D) than to reversed sequence (D-FME, Dutour et al. 2019b). Therefore, the conclusion on syntax use in Great Tits suggested it may not be as clear-cut as for the Japanese Tit and may globally weaken a generalization of syntax results to other species in the genus.

One crucial distinction between the studies of Japanese Tits and Great Tits, however, is that the response of Japanese Tits to the inverted sequence was tested during the nonbreeding season in winter flocks (Suzuki et al. 2016), while these tests were done in a reproductive context at the onset of the breeding season for the Great Tits (Dutour et al. 2019b). The behaviour of Parids is known to vary markedly between seasons. When breeding, they show enhanced individual territoriality and aggressive behaviour (Shedd 1983, Krams and Krama 2002, Samplonius 2018). In contrast, they join other individuals and form flocks in winter (Hinde 1952, Marra et al. 2015). In addition, Great tits approached more heterospecific calls in winter than in the breeding season (Dutour et al. 2019a). The attention paid to the same auditory stimuli therefore seems to be dependent on the reproductive state of 
104 the birds. We can hypothesize that increased aggressiveness toward intruders in spring may

105 directly affect the behavioural response recorded during syntax-related studies (i.e., approach

106 and scanning, Suzuki et al. 2016). In addition, sensibility to conspecific D notes may increase

107 in spring, as pairs use them frequently, and fledglings use similar notes when calling their

108 parents (M.D. pers.obs). In the same way, an increased response toward heterospecific calls

109 (even towards unknown ones, Dutour et al. 2017b) in winter potentially indicates an increased

110 attention towards new calls. As a consequence, different biological conclusions could result

111 from the same experiment done in different parts of the life cycle, even if the general syntax-

112 processing ability of the bird remain the same. On a more global scale, determining whether

113 context can impact conclusions on syntax use in Great Tits could be of value in influencing

114 future studies investigating complex language features in animals.

115 Here, we used field playback experiments to examine whether season has an impact on

116 sensitivity to syntax reversion in Great Tits, allowing us to understand the differences found

117 in the two studies investigating the use of syntax in the family Paridae. Specifically, we

118 recorded the behavioural response of Great tits to either naturally ordered calls, reversed calls,

119 or to a control (background noise) in two seasons: in spring, when territoriality is increased,

120 compared to winter, when individuals join other species in flocks.

\section{METHODS}

\section{Study sites and experimental design}

124 Data were collected at the start of the breeding season when individual territories are

125 established (February/ March 2018, territories are established in February and defended until

126 June in the study population) and during the winter when tits often form mixed-species flocks

127 (November 2018/ January 2019, Hinde 1952), in the north of Lyon, France. 
129 mainly in breeding (i.e., defending a territory, building a nest, rearing a brood of nestlings,

130 Cramp et al. 1993). The defence of the nest against any intruder is intense and well

131 documented (Hinde 1952, Hollander et al. 2008). As winter arrives, Great Tits join small

132 conspecific groups and often heterospecific flocks (Carlson et al. 2020). Even if some

133 dominance relationship remains (Oberski \& Wilson 1991), flocks can combine, and space is

134 divided into undefended overlapping home ranges rather than discrete territories (Ekman

135 1989). Flocks are thought to be an efficient behavioural response toward predator and

136 foraging pressures being different in winter (Sridhar et al. 2009). Indeed, increased food

137 storage to counteract the loss of food supply increases predation risk (increase of body mass

138 being negatively correlated with manoeuvrability, Gosler et al. 1995), while a decrease in

139 individual territory defence whilst not breeding allows birds to gather without strong

140 competition (Morse 1970).

141 In order to examine whether the response of Great Tits was dependent upon season,

142 we conducted three playback types. First, we examined whether tits hearing the combined

143 motifs in the natural order (FME-D calls, natural mobbing call sequence) displayed a

144 combination of the behaviours classically monitored in mobbing studies (approach and scan,

145 see below for more details), and we tested whether this was also the case when the combined

146 motifs were presented in the reverse order (D-FME calls, artificially reversed mobbing call

147 sequence). Finally, we also performed control tests for which the playback contained only

148 background noise (hereafter referred as BN tests). We conducted these tests on 120 adult

149 Great Tits (20 individuals for each call sequence, at two different seasons). 
152 Each test was conducted by two field assistants. One was assigned to the soundtrack

153 preparation and playback operation, while the other was assigned to the observation of the

154 focal bird. After the localization of a focal bird, the loudspeaker was placed $30 \mathrm{~m}$ away from

155 the bird at the bottom of a tree. Both field assistants were positioned opposite each other at

156 vantage points at least $15 \mathrm{~m}$ from the loudspeaker and the focal bird to avoid any perturbation

157 during the test. Prior to playback, the baseline behaviour of the focal bird was observed for at

158 least a one-minute pre-trial period. The playback was started when there was no other

159 passerine observed near the focal individual. If the bird showed alarm behaviour before the

160 test (e.g., gave mobbing calls), or if other birds also responded to the playback, the test was

161 abandoned. The sequence was broadcast using a remotely controlled Shopinnov $20 \mathrm{~W}$

162 loudspeaker with an amplitude of $\sim 80 \pm 3 \mathrm{~dB}(\mathrm{~A})$ (measured at $1 \mathrm{~m}$ from the loudspeaker

163 using Lutron SL-4001, Taipei, Taiwan; C weighting, slow settings, re: $20 \mu \mathrm{Pa}$ ), as this is the

164 natural amplitude of Great Tit mobbing calls (from 77 to $80 \mathrm{~dB}$, Templeton et al. 2016). The

165 background noise observed in the field (mean $\pm \mathrm{sd}=46.1 \pm 2.1 \mathrm{~dB}(\mathrm{C}), n=20$ measurements)

166 associated to the spherical spread and excess attenuation of sound energy radiating from a

167 source in a deciduous forest (Lengagne \& Slater 2002) allowed us to estimate that the

168 broadcast signal reached background noise level at 60-70 $\mathrm{m}$ distance.

169 Subsequently, during one minute of playback treatment, two behavioural variables

170 were recorded, respectively, (1) the vigilance effort with the number of horizontal scans (we

171 counted the number of obvious movements that birds made with their heads from left to right

172 or right to left ( $\sim 180^{\circ}$ turn, Suzuki et al. 2016) and (2) approach within $15 \mathrm{~m}$ of the

173 loudspeaker (Dutour et al. 2017b). Scanning for threats is a stereotyped agitation behaviour

174 (Curio 1975, 1978) commonly measured in studies of mobbing response of tits (e.g., Suzuki

175 et al. 2016, Carlson et al. 2017, Suzuki et al. 2017). Both dense vegetation and the small size 
of these passerine birds prevented a detailed measurement of scanning behaviour using videorecording. These behaviours were thus directly counted an observer using binoculars and reported on a digital audio recorder. To minimize the measurement errors and to make scanning as objective a behaviour as is possible, we considered an individual to scan only if the head movements of the bird from right to left or left to right were obvious. These methods were unable to completely eliminate the potential for unconscious observer bias and we acknowledge that future studies using similar techniques should ideally employ fully blinded designs.

All trials were conducted between 06:00 and 13:00 h during calm and dry weather. On average 10 tests were done each day. Selection of all focal animals was based on location, ensuring successively tested animals were always separated by more than $100 \mathrm{~m}$ to minimize pseudoreplication risk and ensure that tested birds had not heard a previous test, given that the active space of a sound emitted at $80 \mathrm{dBA}$ with a $46 \mathrm{~dB}$ background noise level was less than 100 m (Brenowitz 1982, Lengagne \& Slater 2002).

In addition, we never returned to the same forest path, the size of the research area was large (i.e. $\sim 43 \mathrm{~km}^{2}$ ), and population density in this area is high (M.D. unpubl. data). No bird was seen following us. Hence, although birds were not individually ringed, the probability of testing the same individual twice was low and we are confident that our observations were performed on different individuals.

\section{Playback stimuli and materials}

We used mobbing calls produced by three Great Tits, previously recorded in response to intraspecific mobbing calls (Dutour et al. 2017b). Calls were recorded with a Fostex FR2LE digital recorder (Tokyo, Japan) connected to a Sennheiser ME67-K6 microphone (Wedemark, Germany; see Dutour et al. $2017 \mathrm{~b}$ for more details). We also used mobbing calls obtained 
from the Xeno Canto online database (www.xeno-canto.org) recorded in different European countries $(N=7)$. By controlling several factors when constructing our playbacks (see below), we homogenised our stimuli and reduced potential variation between different geographical areas. We recorded or selected good quality (sampling rate: $44.1 \mathrm{kHz}$; sample size: 16-bits) recordings, and all playback files were saved as .wav files.

From these recording files, we built 20 unique soundtracks of natural mobbing calls (i.e., 20 soundtracks with one individual per soundtrack) using Avisoft-SASLab software (Avisoft Bioacoustics, Glienicke, Germany, one sample of spectrogram and audio file available in Sup.Mat.). These soundtracks were then used to construct the D-FME (i.e. reversed) calls by reversing the motifs order of the original FME-D calls of Great Tits. The

211 same donor individuals were therefore used for both the natural and reversed call sequences.

212 Within each soundtrack, calls were repeated at a rate of 26 calls per minute (characteristics 213 within the range of the natural repetition rates, Dutour et al. 2019b). We used a series of five 214 to eight $\mathrm{D}$ motifs to construct playback (mean $\pm \mathrm{se}=7.11 \pm 0.06)$. In each track, $\mathrm{D}$ notes were 215 placed $82 \pm 40 \mathrm{~ms}$ before FME (no difference with time between FME and D notes in the 216 natural sequence; $t$-test $=1.79, P>0.05)$. All playback sequences were arranged to control the 217 ratio of the D notes over the FME notes in a mobbing call sequence, as note composition is 218 known to alter Great Tits' response (Kalb \& Randler 2019). We also constructed 20 control 219 soundtracks using sections where no birds were calling in the same recordings as natural 220 mobbing calls (BN). In order to avoid pseudoreplication (Kroodsma et al. 1989), each 221 soundtrack was played back only once.

\section{Statistical analysis}

All analyses were carried out in R Studio 1.2.5033 (R core development team 2018) using generalized linear mixed models (GLMM, glmer package lme4). Because the same 
soundtracks were used in both seasons, soundtrack ID was included as a random effect. To analyse the number of horizontal scans, we used a Poisson error distribution, and a log-link function as no overdispersion was detected (overdisp.glmer, package RVAideMemoire). We also included the actual time that the bird had been seen during the one-minute trial as offset $(57.48 \pm 6.36 \mathrm{sec}$, mean $\pm \mathrm{sd})$ and discarded three individuals (all in the spring-natural order

231 call sequence) for which the time was under $20 \mathrm{sec}$ (i.e., sample size for each treatment is 20 ,

232 except for the spring-natural call sequences with $n=17$ ). Approaching behaviour

233 (approaching vs. not approaching, where $1=$ response, $0=$ no response) was analysed using a 234 binomial distribution for the error term. For both behavioural variables, the same three steps of analysis were carried out: (1) 236 we first ran a model with the three treatments (BN, Natural, and Reverse) at each season. We 237 then extracted the estimated marginal means and pairwise comparisons with related effect 238 sizes (package emmeans, function emmeans, and package multcomp, function multcomp::cld). 239 We only focused on five comparisons: in each season, the BN treatment versus the two other 240 treatments, and the difference between the BN treatment in spring and in winter. We therefore 241 used Bonferroni correction with alpha $=0.05 / 5=0.01$. (2) Secondly, we discarded the BN 242 tests and ran a model only with Natural and Reversed treatments in order to test the 243 significance of the interaction term (Season* Treatment, Anova function, package car). This 244 term indicates whether the difference between the two treatments is different between 245 seasons. (3) Finally, we reported the effect sizes of the difference between Natural and 246 Reversed treatments for the two seasons (two comparisons: $\alpha=0.025$ ). The pairwise 247 comparisons and the related effect sizes of the differences were assessed using odds ratio 248 (hereafter OR, odds.ratio, package questionr) for the approach behaviour, and with the 249 exponential effect size for the scanning behaviour (package emmeans and multcompview). 
251 behaviour using Wilcoxon tests for each season and each playback type. As revealed by these 252 analyses, no association between these two behaviours was detected (all $P>0.05$ ).

\section{RESULTS}

\section{Scanning Behaviour}

In both seasons, Great Tits scanned less toward the control treatment $(\mathrm{BN}=$ background noise) than toward the two other call sequences (all $P<0.001$, Fig. 2, Table 1a), except for the reversed call sequences in spring $(P=0.89$, Table 1a). There was no significant difference in scan number between seasons for BN soundtracks $(P=0.03, \alpha=0.01$, Table $1 \mathrm{a})$. control tests were discarded (Table 1b), with a substantially larger difference between acoustic treatments in spring than in winter. Indeed, Great Tits produced 2.29 more scans toward natural calls than toward reversed calls in spring (Table 1c, Fig. 2), while there was no such difference between treatments in winter (ratio of 1.3, Table 1c, Fig. 2). The treatment term was also statistically significant, indicating an overall reduced response to reversed calls $(P<0.001$, Table 1b)

\section{Approaching behaviour}

Respectively $50 \%$ and $65 \%$ of Great Tits approached natural calls in spring and

270 winter. In contrast, only 5\% of Great tits in spring, and none of them in winter, approached

271 toward the controls (Fig 3). The difference between natural calls and controls was statistically

272 significant in both seasons (Table 1a). In contrast, no statically significant difference in

273 probability of approach was detected between reversed calls and controls (35\% in spring, $25 \%$

274 in winter, Fig 3, Table 1a). There was almost no approach exhibited to control playbacks and 
so the difference between controls in spring and in winter was not significant $(P=0.49$, Table 1a).

The interaction between treatment and season was not statistically significant in our model $(P=0.25$, Fig 3 , Table $1 \mathrm{~b})$, but the treatment term was statistically significant (more approach to the natural treatment, $P=0.02$, Fig 3 ). Nonetheless, even though no interaction was detected, we found a statistically significant difference between reversed and natural playback in winter $(\mathrm{OR}=5.57$, Table $1 \mathrm{c})$, but not in spring $(\mathrm{OR}=1.86)$, indicating that Great Tits reduced their response toward reversed calls in winter, but approached both treatments similarly in spring.

\section{DISCUSSION}

Great Tits reduced their overall behavioural response toward reversed calls compared to natural ones. However, season affected the strength of that effect. Great Tits strongly reduced their scanning behaviour when hearing reversed calls compared to natural calls in spring, but such a reduction was not statistically significant in winter. In contrast, for the approach behaviour, the difference between natural and reversed call sequences was statistically significant in winter, but not in spring. The compositional syntax hypothesis requires a decrease in behavioural responses (i.e., scanning and approaching) toward reversed 293 call sequences. Here, we demonstrate that testing birds in different seasons would have resulted in different biological conclusions about syntax-use ability in tits. significant in winter, but not in spring. Importantly however, the interaction in our model was 297 not statistically significant. This may be due to the response variable being binary, thus 298 limiting power to detect effects with the available sample sizes. Nonetheless, the fact that this 
difference was strong in spring but not in winter is some evidence of an effect of season on

300 the response to different treatments by Great Tits. The absence of variation in the probability

301 of approach in spring is consistent with the results of Dutour et al. (2019b) in which the same

302 protocol was used, and could therefore explain the difference with the study of Suzuki et al.

303 (2016), in which birds were tested in winter. These results therefore suggest that season does

304 affect Great Tit behavioural responses to natural and reversed playback.

Seasonal effects on responses to different syntactic forms has previously been

306 demonstrated in birds. For example, a similar result was found by Clucas et al. (2004)

307 investigating the vocal response of Carolina chickadees Poecile carolinensis when confronted

308 with familiar (AAADDD) and unfamiliar order calls (ADADAD): birds discriminated the

309 familiar from the unfamiliar calls in winter, but not in summer. Both Carolina Chickadees and

310 Great Tits live in mixed species flocks during winter (Hinde 1952), which are thought to

311 increase both foraging efficiency and defence against predators (Sridhar et al. 2009).

312 Vigilance toward heterospecific and potentially unfamiliar calls may therefore increase in

313 winter, as contact with heterospecifics with respect to food and alarm calls is common (Morse

314 1970, Clay et al. 2012). Corroborating this hypothesis, Great Tits increased their response

315 toward heterospecifics in winter compared to spring (Dutour et al. 2019a). We can therefore

316 hypothesize that in winter, birds are highly vigilant and more efficient in discriminating

317 unfamiliar calls, consequently leading to high scanning behaviour and low approach

318 behaviour toward artificial sequences. In contrast, during the breeding season, the response of

319 Great Tits is probably linked to strong competition and reproductive investment expressed

320 through increased aggression (Wingfield \& Ramenofsky 1985). This leads to a more risk

321 prone behaviour: approaching toward any calls similar to recruitment calls (i.e., calls with D

322 notes, Kalb et al. 2019) without necessarily scanning. Further research is clearly required to

323 test this hypothesis and to understand why the response to reversed ordering of the mobbing 
324 call sequence varies according to the season. In particular, comparisons of the response to the 325 isolated recruitment call (FME notes) and alarm call (D notes) according to the season is still 326 lacking. Such experimental analysis is required to fully appreciate the underlying reason for 327 scanning and approaching behaviours varying according to the season. Moreover, testing such 328 a hypothesis could help understand whether during the breeding season, Great Tits are indeed 329 more sensitive to recruitment calls, irrespective of the syntactic form.

331 approach behaviour when hearing reversed calls. On the opposite, the reduced scanning 332 response was statistically significant in spring, but not in winter. Consequently, the same 333 experiment done in different seasons would not have led to the same biological conclusions.

334 Indeed, approaching and scanning more toward natural mobbing call sequences than toward 335 reversed call sequences is an essential prerequisite for compositional syntax in birds (Suzuki 336 et al. 2016). Concluding whether Great Tits do truly use syntax is consequently difficult: it is 337 unlikely that high mental ability such as syntax use vary with the seasons; but we show that 338 the external proof of it (the bird's behaviour) does. This may reflect a change of priorities in 339 birds between seasons (heterospecific co-operation in winter versus high territorial defence in 340 spring). In fact, such a problem may be common in language-related studies of animal 341 behaviour (Graham et al. 2019). For example, deciphering whether chimpanzees Pan 342 troglodytes possess a zero or second order intentionality level (i.e., when the sender does or 343 does not intend to signal and attribute mental state to the receiver; Townsend et al. 2017) is 344 dependent on aspects of predator stimuli (Crockford et al. 2012, Schel et al. 2013, Graham et 345 al. 2019). Even if the effect sizes of the differences varied between the two seasons, we found an 347 overall reduced response in both scanning and approaching behaviours in response to the 348 reversed mobbing calls. This is consistent with previous studies of bird syntax (Suzuki et al. 
2016, 2017, Dutour et al. 2019b). Discussion of whether this reduced response does support

350 the presence of compositional syntax in birds has been intense (see Bolhuis et al. 2018a,

3512018 b, Suzuki et al. 2018). Indeed, active use of compositional syntax by birds or simpler

352 mechanisms such as the masking hypothesis (D notes put in the first place acoustically hiding 353 the FME notes, Dutour et al. 2019b, Dutour et al. 2020) are still to be tested. We advocate for 354 the monitoring of other fine behavioural cues such as wing flicking, tail flit or calling in order 355 to provide a more reliable overview of the bird's internal state, (Cully \& Ligon 1976, Carlson 356 et al. 2017, Salis et al. 2020). Other lines of inquiry, for example in neurobiology, may

357 complete field data and allow a broader view of birds' abilities (Marler 2004). Experiments on 358 Black-capped Chickadees Poecile atricapillus brains have shown, for example, that the neural 359 response (i.e., protein expression important for processing and categorizing conspecific 360 vocalizations) increased with the level of threat conveyed in the calls (Avey et al. 2011).

361 Consequently, going one step further by studying neural responses to different syntactic forms 362 and thus, the neural mechanisms underlying the production and perception of call 363 combinations could be investigated (Suzuki et al. 2019a). In conclusion, context can affect the behavioural cues used to assess syntax understanding by Great Tits, and thus affect biological conclusions about syntax use in this

367 species. Thorough work on the impact of context on animal behaviour could turn out to be of 368 critical importance and directly impact future studies investigating high cognitive processing 369 in non-human animals. 
373 This work was supported by French Ministry of Research and Higher Education funding (to

374 M.D. PhD grants 2015-2018). We are thankful to the Fondation Vérots for the authorization

375 of fieldwork on their protected grounds. We are grateful to Sarah Walsh for English language

376 checking. We also thank the three anonymous reviewers for helpful comments on our

377 manuscript. Authors comply with The European Code of Conduct for Research Integrity. We

378 have no conflict of interest to declare. The raw data used for the statistical analysis can be

379 provided by A.S. upon request.

\section{REFERENCES}

Avey, M. T., Hoeschele M., Moscicki M.K., Bloomfield L.L. \& Sturdy, C.B. 2011. Neural

Correlates of Threat Perception: Neural Equivalence of Conspecific and Heterospecific

Mobbing Calls Is Learned. PLoS One 6: e23844.

Bolhuis, J. J., Beckers G.J.L., Huybregts, M.A.C., Berwick R.C. \& Everaert, M.B.H. 2018a. Meaningful syntactic structure in songbird vocalizations? PLoS Biol. 16: e2005157.

Bolhuis, J. J., Beckers G.J.L., Huybregts, M.A.C., Berwick R.C. \& Everaert, M.B.H.

3892018 b. The slings and arrows of comparative linguistics. PLoS Biol. 16: e3000019.

390 Bradbury, J.W. \& Vehrencamp, S.L. 2011. Principles of animal communication, 2nd

391 edition. Sunderland: Sinauer Associates.

392 Brenowitz, E. A. 1982. The active space of red winged blackbird song. J. Comp. Physiol. 393 147: 511-522.

394 Carlson, N. V., Healy S.D. \&Templeton, C.N. 2018. Mobbing. Curr. Biol. 28:

395 R1081-R1082. 
Carlson, N. V., Pargeter H.M. \&Templeton, C.N. 2017. Sparrowhawk movement, calling, 397 and presence of dead conspecifics differentially impact Blue Tit (Cyanistes caeruleus) vocal 398 and behavioral mobbing responses. Behav. Ecol. Sociobiol. 71: 133.

399 Carlson, N. V., Healy, S. D. \& Templeton, C. N. 2020. What makes a 'community 400 informant'? Reliability and anti-predator signal eavesdropping across mixed-species flocks of 401 tits. Anim. Behav. Cogn. 7: 214-246.

402 Catchpole, C. K. \& Slater, T. L. B. 1995. Bird song: Themes and variations. Cambridge: 403 Cambridge University Press.

404 Clay, Z., Smith, C.L. \& Blumstein, D.T. 2012. Food-associated vocalizations in mammals 405 and birds: What do these calls really mean? Anim. Behav. 83: 323-330.

406 Clucas, B.A., Freeberg, T.M. \& Lucas, J.R. 2004. Chick-a-Dee Call Syntax, Social 407 Context, and Season Affect Vocal Responses of Carolina Chickadees (Poecile Carolinensis). 408 Behav. Ecol. Sociobiol. 55: 187-96.

409 Cramp, S., Perrins, C. M. \& Brooks, D. J. 1993. Handbook of the birds of Europe the 410 middle east and north Africa Vol. 7: Flycatchers to shrikes. Oxford and New York: Oxford 411 University Press.

412 Crockford, C., Wittig, R.M., Mundry, R. \& Zuberbühler, K. 2012. Wild Chimpanzees 413 Inform Ignorant Group Members of Danger. Curr. Biol. 22: 142-146.

414 Cully, J. F. \& Ligon, J.D. 1976. Comparative Mobbing Behavior of Scrub and Mexican 415 Jays. Auk 93: 116-125.

416 Cumming, G., Fidler, F. \& Vaux, D. L. 2007. Error bars in experimental biology. J. Cell 417 Biol. 177: 7-11.

418 Cumming, G. \& Finch, S. 2005. Inference by Eye: Confidence Intervals and How to Read 419 Pictures of Data. Am. Psychol. 60: 170-180. 
Curio, E. 1975. The functional organization of anti-predator behaviour in the pied flycatcher:

421 a study of avian visual perception. Anim. Behav, 23: 1-115.

422 Curio, E. 1978. The adaptive significance of avian mobbing: I. Teleonomic hypotheses and 423 predictions. Ethology 48: 175-183.

424 Curio, E. \& Regelmann, K. 1986. Predator harassment implies a real deadly risk: A reply to 425 Hennessy. Ethology 72: 75-78.

426 Dutour, M., Cordonnier, M., Léna, J.-P. \& Lengagne, T. 2019a. Seasonal variation in 427 mobbing behavior of passerine birds. J. Ornithol. 160: 509-514.

428 Dutour, M., Léna, J.-P. \& Lengagne, T. 2016. Mobbing behavior varies according to 429 predator dangerousness and occurrence. Anim. Behav. 119: 119-124.

430 Dutour, M., Léna, J.-P. \& Lengagne, T. 2017b. Mobbing calls: a signal transcending 431 species boundaries. Anim. Behav. 131: 3-11.

432 Dutour, M., Léna, J.-P. \& Lengagne, T. 2019b. Syntax manipulation changes perception of 433 mobbing call sequences across passerine species. Ethology 125: 635-644.

434 Dutour, M., Suzuki, T.N. \& Wheatcroft, D. 2020. Great tit responses to the calls of an 435 unfamiliar species suggest conserved perception of call ordering. Behav. Ecol. Sociobiol. 74: $436 \quad 1-9$.

437 Ekman, J. 1989. Ecology of Non-Breeding Social Systems of Parus. Wilson Bull. 101: 263438288.

439 Engesser, S., Ridley, A.R. \& Townsend, S.W. 2016. Meaningful call combinations and 440 compositional processing in the southern pied babbler. Proc. Natl. Acad. Sci. U.S.A. 113: $441 \quad 5976-5981$.

442 Engesser, S. \& Townsend, S.W. 2019. Combinatoriality in the vocal systems of nonhuman 443 animals. Wires. Dev. Biol. 10: e1493. 
Fishbein, A.R., Fritz, J.B., Idsardi, W.J. \& Wilkinson, G.S. 2019. What can animal communication teach us about human language? Philos. T. Roy. Soc. B 375: 20190042. fat. Nature 377: 621-623.

Graham, K. E., Wilke, C., Lahiff, N.J. \& Slocombe, K.E. 2019. Scratching beneath the surface: intentionality in great ape signal production. Philos. T. Roy. Soc. B 375: 20180403.

Griesser, M. 2008. Referential Calls Signal Predator Behavior in a Group-Living Bird

451 Species. Curr. Biol. 18: 69-73.

Griesser, M., Wheatcroft, D. \& Suzuki, T.N. 2018. From bird calls to human language: exploring the evolutionary drivers of compositional syntax. Curr. Opin. Behav. Sci. 21: 6-12.

Hauser, M. D., Chomsky, N. \& Fitch, W.T. 2002. The Faculty of Language: What Is It, 455 Who Has It, and How Did It Evolve? Science 298: 1569-79.

Hinde, R. A. 1952. The Behavior of the Great Tit (Parus major) and Some Other Related Species. Behaviour 2: 1-201.

Hollander, F. A., Van Overveld, T., Tokka, I. \& Matthysen, E. 2008. Personality and Nest Defence in the Great Tit (Parus major). Ethology 114: 405-412.

Hurd, C. R. 1996. Interspecific attraction to the mobbing calls of Black-Capped Chickadees (Parus atricapillus). Behav. Ecol. Sociobiol. 38: 287-292.

Hurford, J.R. 2011. The linguistic theory of numerals. Cambridge: Cambridge University 463 Press.

464 Johansson, U. S., Ekman, J., Bowie, R. C., Halvarsson, P., Ohlson, J. I., Price, T. D., \& 465 Ericson, P. G. 2013. A complete multilocus species phylogeny of the tits and chickadees 466 (Aves: Paridae). Mol. Phylogenetics Evol. 69: 852-860.

467 Kalb, N., Anger, F. \& Randler, C. 2019. Great Tits encode contextual information in their 468 food and mobbing calls. R. Soc. Open Sci. 6: 191210. 
Kalb, N. \& Randler, C. 2019. Behavioral Responses to Conspecific Mobbing Calls Are

470 Predator-specific in Great Tits (Parus major). Ecol. Evol. 9: 9207-13.

471 Krams, I. \& Krama, T. 2002. Interspecific reciprocity explains mobbing behavior of the

472 breeding chaffinches, Fringilla coelebs. Proc. R. Soc. Lond. B. 269: 2345-2350.

473 Kroodsma, D. E. 1989. Suggested experimental designs for song playbacks. Anim. Behav.

474 37: 600-609.

475 Lengagne, T. \& Slater, P.J.B. 2002.The effects of rain on acoustic communication: tawny

476 owls have good reason for calling less in wet weather. Proc. R. Soc. Lond. B. 269: 2121-

4772125.

478 Marler, P. 2004. Bird Calls: Their Potential for Behavioral Neurobiology. Ann. N. Y. Acad.

479 Sci. 1016: 31-44.

480 Marra, P. P., Cohen, E.B., Loss, S.R., Rutter, J.E. \& Tonra, C.M. 2015. A call for full 481 annual cycle research in animal ecology. Biol. Lett. 11: 20150552.

482 Morse, D. H. 1970. Ecological Aspects of Some Mixed-Species Foraging Flocks of Birds. 483 Ecol. Monogr. 40: 119-168.

484 Oberski, I. M., \& Wilson, J. D. 1991. Territoriality and site-related dominance: on two 485 related concepts in avian social organization. Ethology 87: 225-236.

486 Päckert, M., Martens, J., Eck, S., Nazarenko, A.A., Valchuk, O.P., Petri, B. \& Veith, M. 487 2005. The great tit (Parus major) - a misclassified ring species. Biol. J. Linn. Soc. 86: $488 \quad 153-174$.

489 Randler, C. \& Vollmer, C. 2013. Asymmetries in commitment in an avian communication 490 network. Sci. Nat. 100: 199-203.

491 R Core Development Team (2018). R: A Language and Environment for Statistical 492 Computing. R Foundation for Statistical Computing, Vienna, Austria. https://www.R493 project.org/ 
Salis, A., Léna, J. P. \& Lengagne, T. (2020). Great tits (Parus major) adequately respond to

495 both allopatric combinatorial mobbing calls and their isolated parts. Ethology 00:1-10.

496 Samplonius, J.M. Interspecific aggression declines seasonally in breeding great tits Parus

497 major. 2018. Ethology 00:1-5

498 Schel, A. M., Townsend, S.W., Machanda, Z., Zuberbühler, K. \& Slocombe, K.E. 2013.

499 Chimpanzee Alarm Call Production Meets Key Criteria for Intentionality. PLoS One 8:

$500 \quad \mathrm{e} 76674$.

501 Searcy, W. A. 2019. Animal communication, cognition, and the evolution of language. Anim.

502 Behav. 151: 203-205.

503 Seyfarth, R. M. \& Cheney, D.L. 2003. Signalers and Receivers in Animal Communication.

504 Annu. Rev. Phychol. 54: 145-173.

505 Shedd, D. H. 1983. Seasonal Variation in Mobbing Intensity in the Black-Capped Chickadee.

506 Wilson J. Ornithol. 95: 343-348.

507 Sridhar, H., Beauchamp, G. \& Shanker, K. 2009. Why do birds participate in mixed-

508 species foraging flocks? A large-scale synthesis. Anim. Behav. 78: 337-347.

509 Suzuki, T. N., Griesser, M. \& Wheatcroft, D. 2019a. Syntactic rules in avian vocal

510 sequences as a window into the evolution of compositionality. Anim. Behav.151: 267-274.

511 Suzuki, T. N., Wheatcroft, D. \& Griesser, M. 2016. Experimental evidence for

512 compositional syntax in bird calls. Nat. Commun. 7: 10986.

513 Suzuki, T. N., Wheatcroft, D. \& Griesser, M. 2017. Wild Birds Use an Ordering Rule to

514 Decode Novel Call Sequences. Curr. Biol. 27: 2331-2336.e3.

515 Suzuki, T. N., Wheatcroft, D. \& Griesser, M. 2018. Call combinations in birds and the

516 evolution of compositional syntax. PLoS Biol. 16: e2006532.

517 Suzuki, T. N., Wheatcroft, D. \& Griesser M. 2019b. The syntax-semantics interface in

518 animal vocal communication. Philos. T. Roy. Soc. B 375: 20180405. 
Templeton, C.N., Zollinger, S.A. \& Brumm, H. 2016. Traffic noise drowns out Great Tit

520 alarm calls. Curr. Biol., 26: R1173-R1174.

521 Townsend, S. W., Koski, S.E., Byrne, R.W., Slocombe, K.E., Bickel, B., Boeckle, M., 522 Braga Goncalves, I., Burkart, J.M., Flower, T., Gaunet F., et al. 2017. Exorcising Grice’s 523 ghost: An empirical approach to studying intentional communication in animals. Biol. Rev. 524 92: 1427-1433.

Townsend, S.W., Engesser, S., Stoll, S., Zuberbühler K. \& Bickel B. 2018.

Compositionality in animals and humans. PLoS Biol. 16: e2006425.

527

Tyack, P. L. 2019. A taxonomy for vocal learning. Philos. T. Roy. Soc. B 375: 20180406.

Wilbrecht, L. \& Nottebohm F. 2003. Vocal learning in birds and humans. Ment. Retard. Dev. D. R. 9: 135-148.

Wingfield J.C. \& Ramenofsky M. 1985. Testosterone and Aggressive Behaviour during the Reproductive Cycle of Male Birds. In Neurobiology: Current Comparative Approaches. (R. Gilles, J. Balthazart, Editors). Berlin: Springer.

Zuberbühler, K. 2019a. Evolutionary roads to syntax. Anim. Behav. 151: 269-265.

Zuberbühler, K. 2019b. Syntax and compositionality in animal communication. Philos. T. Roy. Soc. B. 375: 20190062.

\section{SUPPORTING INFORMATION}

Figure 1. Spectrograms of call treatment played to Great Tits. (a) FME-D calls and (b) DFME calls, which are a reversed combination of FME and D calls. These calls were digitally edited using AvisoftSASLab Pro software.

Table 1. Overview of the playback stimuli used for the study. $\mathrm{XC}$ is the acronym for xenocanto. 
544 Table 1. Details of the pairwise comparisons (a, c) and model output (b). (a) Refers to the 545 comparisons with the control (BN), (b) to the model in which control tests were discarded, 546 and (c) to the comparison between natural and reversed calls in the two seasons studied. For 547 scanning behaviour, the ratio (effect size) indicates the strength of the difference between the 548 first and the second term (e.g., Great Tits scanned on average 1.44 times more toward 549 background noise in spring than in winter). The same reasoning applies for the odds ratio 550 (OR) for the approach behaviour. A GLMM with a Poisson error distribution was used for the 551 number of scans $\left(\sim 180^{\circ}\right.$ horizontal head turns $)$ during $1 \mathrm{~min}$. A GLMM with a binomial error 552 distribution was used for approach behaviour. The pairwise comparisons were extracted from 553 the model and $P$-values were corrected for multiple comparisons (Bonferroni correction: $\alpha=$ 5540.01 for (a), $\alpha=0.05$ for (b), and $\alpha=0.025$ for (c) due to correction for multiple 555 comparisons). se, standard error; $z$, z statistic; $P$, p-value (bold= statistically significant); $\chi^{2}$, 556 Chi-squared test; df, degree of freedom; 95\%CI, 95\% confidence intervals.

\begin{tabular}{ccccc} 
& \multicolumn{5}{c}{ SCAN } \\
\cline { 2 - 5 } (a) Differences with control BN & Ratio & se & $\boldsymbol{Z}$ & $\boldsymbol{P}$ \\
\hline BN Winter- BN Spring & 1.44 & 0.24 & 2.2 & 0.03 \\
BN Winter- Natural Winter & 3.13 & 0.53 & 6.8 & $<\mathbf{0 . 0 0 1}$ \\
BN Winter- Reversed Winter & 2.41 & 0.41 & 5.11 & $<\mathbf{0 . 0 0 1}$ \\
BN Spring - Natural Spring & 2.34 & 0.36 & 5.46 & $<\mathbf{0 . 0 0 1}$ \\
BN Spring- Reversed Spring & 1.02 & 0.17 & 0.13 & 0.89 \\
\hline (b) Model discarding BN tests & $\mathbf{X}$ & $\mathbf{d f}$ & $\boldsymbol{P}$ & \\
\hline Season (Spring or Winter) & 3.52 & 1 & 0.06 & \\
Treatment (Natural or Reversed) & 18.26 & 1 & $<\mathbf{0 . 0 0 1}$ & \\
Season* Treatment & 11.49 & 1 & $<\mathbf{0 . 0 0 1}$ & \\
\hline (c) Difference Natural-Reversed calls & Ratio & se & $\boldsymbol{Z}$ & $\boldsymbol{P}$ \\
\hline Natural Winter- Reversed Winter & 1.3 & 0.18 & 1.92 & 0.05 \\
Natural Spring- Reversed Spring & 2.29 & 0.35 & 5.45 & $<\mathbf{0 . 0 0 1}$
\end{tabular}

\begin{tabular}{cccc}
\multicolumn{5}{c}{ APPROACH } \\
\hline OR & 95\%Cl & $\boldsymbol{z}$ & $\boldsymbol{P}$ \\
\hline 3.15 & {$[0.12 ; 82.17]$} & 0.69 & 0.49 \\
73.8 & {$[3.89 ; 1401.64]$} & 2.86 & 0.004 \\
14.54 & {$[0.75 ; 283.38]$} & 1.77 & 0.08 \\
19 & {$[2.12 ; 170.39]$} & 2.63 & $\mathbf{0 . 0 0 8}$ \\
10.23 & {$[1.12 ; 93.35]$} & 2.06 & 0.04 \\
\hline $\mathbf{X}^{2}$ & $\mathbf{d f}$ & $\boldsymbol{P}$ & \\
\hline 0.05 & 1 & 0.82 & \\
\hline 5.64 & 1 & $\mathbf{0 . 0 2}$ & \\
1.33 & 1 & 0.25 & \\
\hline OR & $\mathbf{9 5 \% C l}$ & $\boldsymbol{z}$ & $\boldsymbol{P}$ \\
\hline 5.57 & {$[1.42 ; 21.86]$} & 2.46 & $\mathbf{0 . 0 1}$ \\
\hline 1.86 & {$[0.52 ; 6.61]$} & 0.96 & 0.33
\end{tabular}


560

561

562

563

564

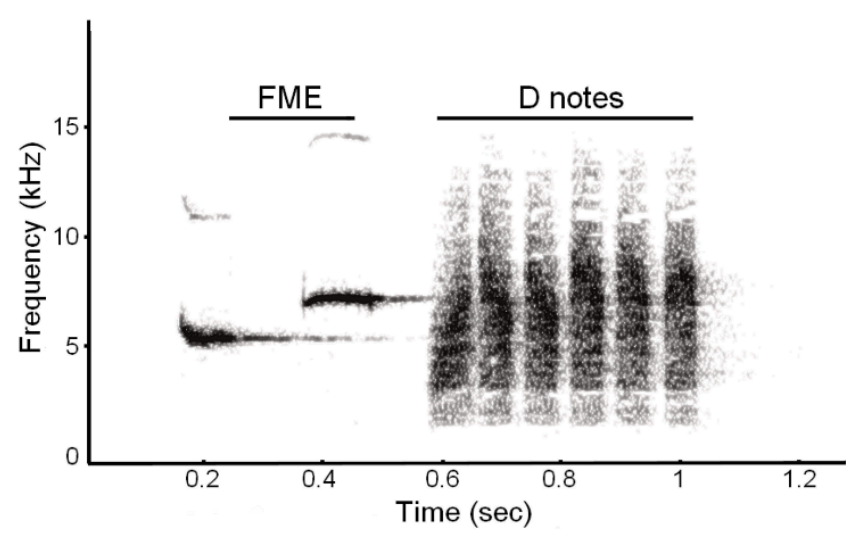

565

566 Figure 1. Sonogram of a Great Tit mobbing call, comprising two distinct calls: (i) alert call

567 (composed of Frequency Modulated Elements, FME) and (ii) recruitment call (a string of

568 notes with broadband frequencies, D notes). This mobbing call was produced with Avisoft-

569 SASLab.

570

571

572

573

574 


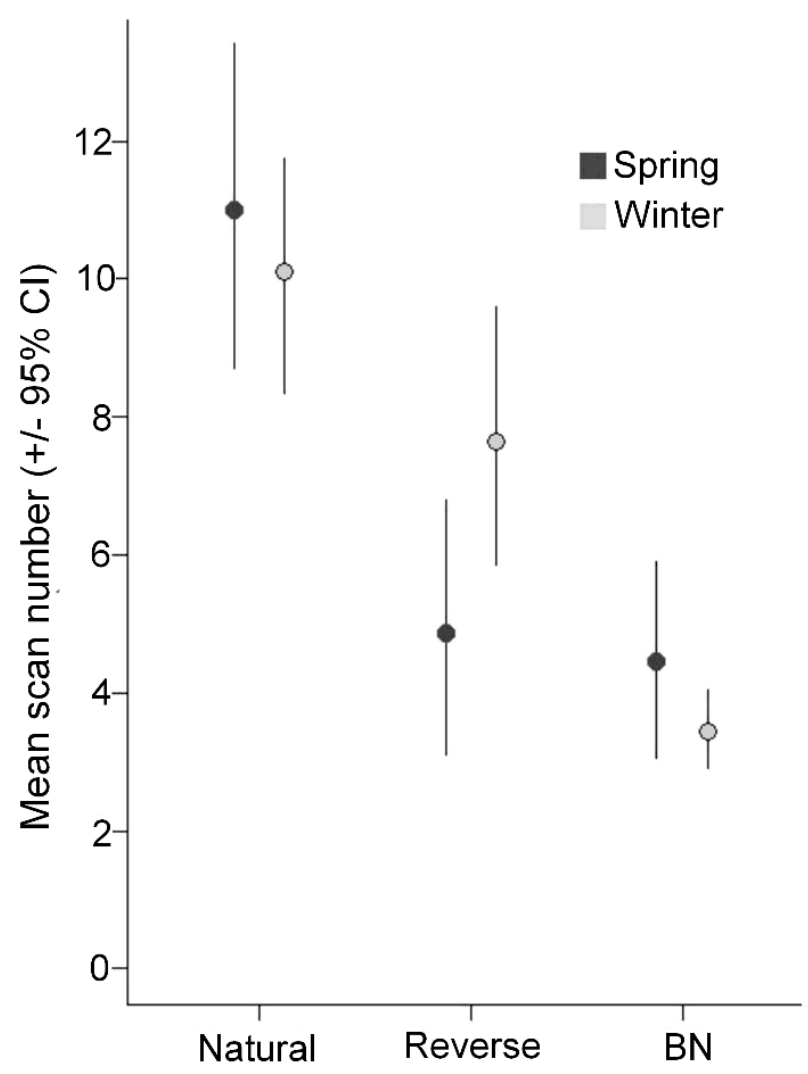

586 Figure 2. Mean number of scans (horizontal head movement of $\sim 180^{\circ}$ ) produced in $1 \mathrm{~min}$ by

587 Great Tits as a function of the call sequence used and the Season ( $\pm 95 \%$ boot-strapped

588 Confidence Intervals). Great Tit mobbing calls in their natural order (FME-D) are compared

589 to reversed calls (D-FME) and to Background Noise (BN). Statistical inference was made

590 using confidence intervals: difference is statistically significant when less than half of the CI

591 overlap (Cumming \& Finch 2005, Cumming 2007).

592

593

594

595

596 


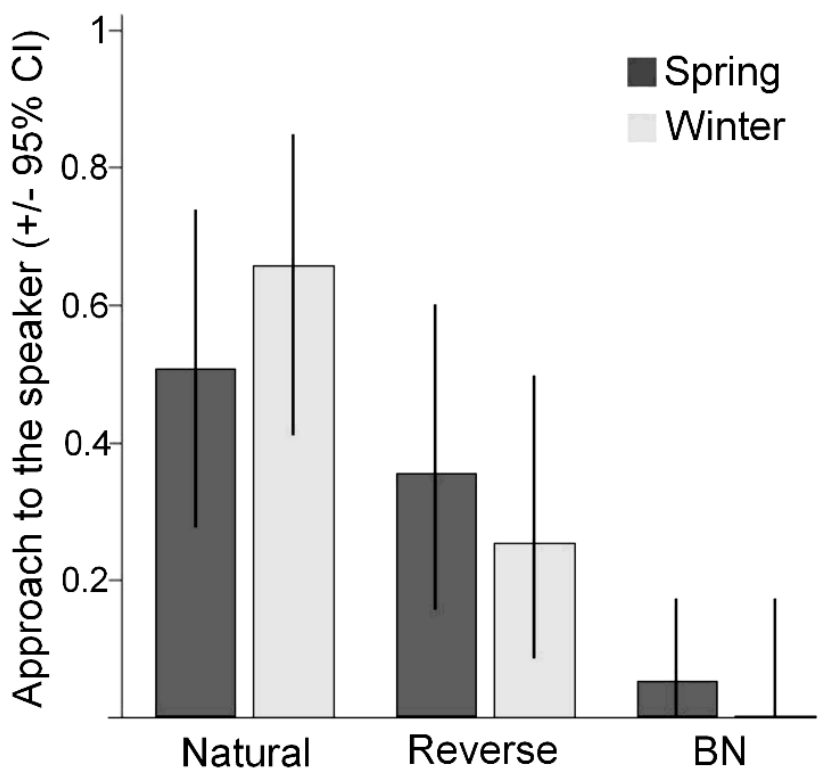

604

605 Figure 3. Percentage of individuals $( \pm 95 \% \mathrm{CI})$ approaching the speaker as a function of the

606 call sequence and the season. Great Tit mobbing calls in their natural order (FME-D) are

607 compared to reversed calls (D-FME) and to Background Noise (BN). Statistical inference can

608 be made using the confidence intervals: the difference is statistically significant when less

609 than half of the CI overlap (Cumming \& Finch 2005, Cumming 2007).

610 